\title{
Could Assistive Technology Provision Models Help Pave the Way for More Environmentally Sustainable Models of Product Design, Manufacture and Service in a Post-COVID World?
}

\author{
Ben Oldfrey ${ }^{1,2, *}$, Giulia Barbareschi ${ }^{1,3}{ }^{\oplus}$, Priya Morjaria ${ }^{4}\left(\mathbb{D}\right.$, Tamara Giltsoff ${ }^{1}$, Jessica Massie ${ }^{4}$, \\ Mark Miodownik ${ }^{2}$ D and Catherine Holloway ${ }^{1,3}$ (D) \\ 1 Global Disability Innovation Hub (GDI Hub), London E15 2GW, UK; giulia.barbareschi.14@ucl.ac.uk (G.B.); \\ t.giltsoff@gmail.com (T.G.); c.holloway@ucl.ac.uk (C.H.) \\ 2 Institute of Making, University College London, London WC1E 7JE, UK; m.miodownik@ucl.ac.uk \\ 3 University College London Interaction Centre (UCLIC), London WC1E 6EA, UK \\ 4 International Centre for Eye Health, Clinical Research Department, London School of Hygiene and Tropical \\ Medicine, London WC1E 7HT, UK; priya.morjaria@lshtm.ac.uk (P.M.); \\ Jessica.Massie1@student.lshtm.ac.uk (J.M.) \\ * Correspondence: b.oldfrey@ucl.ac.uk
}

Citation: Oldfrey, B.; Barbareschi, G.; Morjaria, P.; Giltsoff, T.; Massie, J.; Miodownik, M.; Holloway, C. Could Assistive Technology Provision Models Help Pave the Way for More Environmentally Sustainable Models of Product Design, Manufacture and Service in a Post-COVID World?. Sustainability 2021, 13, 10867. https://doi.org/10.3390/ su131910867

Academic Editor: Lucian-Ionel Cioca

Received: 16 July 2021

Accepted: 26 September 2021

Published: 30 September 2021

Publisher's Note: MDPI stays neutral with regard to jurisdictional claims in published maps and institutional affiliations.

Copyright: (c) 2021 by the authors. Licensee MDPI, Basel, Switzerland. This article is an open access article distributed under the terms and conditions of the Creative Commons Attribution (CC BY) license (https:/ / creativecommons.org/licenses/by/ $4.0 /)$.

\begin{abstract}
From multiple studies conducted through the FCDO AT2030 Programme, as well as key literature, we examine whether Assistive Technology (AT) provision models could look towards more sustainable approaches, and by doing this benefit not only the environment, but also address the problems that the current provision systems have. We show the intrinsic links between disability inclusion and the climate crisis, and the particular vulnerability people with disabilities face in its wake. In particular, we discuss how localised circular models of production could be beneficial, facilitating context driven solutions and much needed service elements such as repair and maintenance. Key discussion areas include systems approaches, digital fabrication, repair and reuse, and material recovery. Finally, we look at what needs be done in order to enable these approaches to be implemented. In conclusion, we find that there are distinct parallels between what AT provision models require to improve equitable reliable access, and strategies that could reduce environmental impact and bring economic benefit to local communities. This could allow future AT ecosystems to be key demonstrators of circular models, however further exploration of these ideas is required to make sense of the correct next steps. What is key in all respects, moving forward, is aligning AT provision with sustainability interventions.
\end{abstract}

Keywords: assistive technology; disability; inclusion; circular economy; sustainability; localization; distributed manufacturing; low resource settings; repair; production

\section{Introduction}

Assistive Technology (AT) is defined by the WHO as "an umbrella term covering the systems and services related to the delivery of assistive products and services" [1]. This definition makes clear that AT not only includes the physical and digital products used by people with disabilities, but also the systems and services that are necessary to the provision of these products.

Over one billion people need one or more assistive devices, with a projected two billion in need by 2050 ; yet only $5-15 \%$ of assistive technology needs are currently met [2]. At the same time, global demand for resources at large is projected to double by 2050, all the while the climate crisis rages on [3].

Globalisation, particularly the pairing of mass production and global supply chains, is a hugely effective model for the provision of manufactured goods. However, it also leads to a reduction in the number of independent products and services available to customers, e.g., in the hearing aid and eyeglasses markets [4,5], with a lack of context 
specific product development. It also creates a global supply chain that is vulnerable to disruption. The fragility of supply chains has been exposed during the COVID-19 pandemic, where the global provision of healthcare products-PPE, medical devices, oxygen, vaccines and other pharmaceuticals have been shown to be highly problematic when global supply chains break down [6]. The result has been a lack of equitable access to healthcare and healthcare products. AT has been particularly affected by the supply chain disruption and a lack of local service provision during the pandemic [7]. However, it has also allowed society to experience the challenges that people with disabilities face-exclusion and isolation [8]. There is then an interesting confluence where society's requirements for more robust, local solutions is coinciding with the technological progress on the circular economy that can provide it.

The provision of AT is essential to each of the United Nation's Sustainable development goals (SDGs) [9]. Nilsson et al. show that implicit in the SDG logic is that the goals depend on each other-but no one has specified exactly how [10]. They state that if countries ignore the overlaps and simply start trying to tick off targets one by one, they risk perverse outcomes. If mutually reinforced actions are not taken and trade-offs minimised, the agenda will not be able to deliver on its potential [10]. Global AT provision is a good example of where reinforced actions are important. It is estimated there will be 2 billion people requiring one or more assistive products by 2050 [11], but with the projected rise in climate change induced natural disasters bringing higher risk of severe trauma and injury to communities around the world-this number could increase further still [12]. Therefore, it is essential that AT provision is realised using a sustainable approach.

Although the environmental responsibility should not be placed at the door of the poorest consumers, Khavul and Bruton argue that "for those living at the bottom of the economic ladder in developing countries, sustainability enhancing innovations can resolve the logjam at the intersection of sustainability, poverty, and the environment. However, for such innovations to stick, they need to be designed with local customers, networks, and business ecosystems in mind" [13]. If this is not the case, then businesses run the risk of introducing innovations that repeatedly fail to be adopted, and never cross the last mile of the innovation journey [14].

\section{Aims of This Paper}

By drawing upon multiple studies conducted through AT2030 and partner programmes, as well as relevant literature, we examine whether AT provision models could take advantage of the shifts that are occurring due to the COVID-19 pandemic, towards more sustainable models of AT provision. We argue that more circular models of production could benefit not only the environment, but users of AT and those who could yet benefit from AT. The current provision systems are failing to meet the global need [15]. Part of the reason for this is the monopoly that the globalised model has, in which AT is designed, manufactured, distributed, provided and explained to users, repaired, upgraded, and adapted [16]. We ask if many of the problems currently identified within AT provision could be combated if more of the AT value chain was located nearer the end users.

In this paper we aim to initiate more tangible discussion on the way forward to sustainable models of AT provision. We do this from the perspective of how sustainable approaches could also mean better provision overall.

By moving more of the AT value chain to a local setting, the route to user-led innovation and context-driven solutions can be facilitated. This potentially reduces the environmental impact of AT provision too, but it may still lead to perverse outcomes. In this paper we therefore seek to explore the potential of a more circular approach to AT and weigh up the advantages and drawbacks.

\section{Methods and Content}

Layout of the rest of the paper:

Section 4. The Relationship between Disability Inclusion and Environmental Sustainability. 
Section 5. Circular Model of AT Provision.

Section 6. Potential Opportunities in a Systems Approach to Local Production of AT.

Section 7. Innovation Opportunity Areas that Could Allow Increased and Sustainable AT Provision:

Section 7.1. Potential of Digital Fabrication;

Section 7.2. Repair of AT;

Section 7.3. Reuse Strategies;

Section 7.4. Material Efficiency and Recovery from AT.

Section 8. Conclusion:

Section 8.1. What needs to be done;

Section 8.2. Concluding Summary and Final Remarks.

To explore these ideas, we begin in Section 4 by looking at the intrinsic relationship between disability inclusion and sustainability, and the effect the climate crisis is having on the global disabled population, and therefore stakeholders operating in these different missions need to pay better attention to each other.

In Section 5, we discuss the circular economy and introduce what a more circular model of AT provision could look like.

In Section 6, we make the case for the potential of increased localisation to enable systems approaches to AT provision as an answer to the issues that various stakeholders see from their perspective given in two scoping studies done by AT2030. Specifically we look at local production systems and the unified potential they hold in addressing these co-missions.

The first is a scoping study into current issues and innovation in prosthetics [17]. For this, we conducted semi-structured interviews with 12 stakeholders in the field across industry and academia. We similarly conducted a study with the aim to understanding the barriers and facilitators to delivering innovation in the area of refraction care and delivery of eyeglasses in LMICs [5]. For this, 8 semi-structured interviews were undertaken with entrepreneurs who are active in the delivery of eyeglasses in low- and middle-income settings. Across both of these studies, these stakeholders primarily operate in LMICs with particular presence in East and Southern Africa, and South East Asia, as well as India and Sri Lanka.

In Section 7, we then look at specific innovation opportunity areas that could be further encouraged in AT strategies to allow increased and sustainable AT provision: starting with (a) Potential of digital fabrication; (b) Repair of AT; (c) Re-use strategies; and finally (d) Material efficiency and recovery in AT.

Finally, in Section 8, we discuss what is needed to critically appraise and push these ideas forward, and conclude with reflections on the originally posed question.

Where appropriate across sections, we also draw upon case studies from the AT Impact fund, which is currently being supported by a part of AT2030, which aims to foster technology solutions to reach people with disabilities in Africa, and to test business models that are most likely to succeed.

\section{The Relationship between Disability Inclusion and Environmental Sustainability}

While the focus of this paper is how the two missions of AT innovation and sustainability can and should be aligned, it is important to recognise the causal relationship between climate change and disability. Several authors have highlighted how people with disabilities are more likely to be vulnerable to the negative effects of climate change [18-21], whilst this group could also represent an invaluable resource to help develop better strategies for climate resilience, equality and sustainability [22-25].

Climate change has been linked to food and energy shortages, increased likelihood of dangerous weather events, freshwater scarcity, global health threats and many other negative consequences that disproportionally affect people who are socially vulnerable because of their gender, socio-economic status or disability [26]. As shown by numerous 
researchers, poverty and disability are closely intertwined in a vicious cycle that exacerbates inequality and negatively affects the individual leading to limited access to education, inability to access work and social opportunities, and reduced health outcomes which are likely to lead to worsening of disability $[27,28]$.

These intersecting vulnerabilities put people with disabilities at particular risk of negative consequences of climate change, and the relevance of this risk is increased both during and after environmental disasters, which are increasing in prevalence due to the climate crisis [29]. Drawing on the experiences of both the tsunamis that devastated much of the coastal regions of South Asia on the 26 December 2004and the Hurricane Katrina which hit the Southern US between the 25 and 29 August 2005, Priestley and Hemingway [29] highlight how the difficulties experienced by people hit by these two natural disasters increase for people with disabilities. Forced and unplanned displacement causes loss of access to essential services; sudden separation from family members means that people with disabilities find themselves without primary caregivers who, in case of people with severe disability are often the only economic provider granting financial assistance; the reduced availability of education or work opportunity is often liked to increased discrimination [29]. Furthermore, in the same fashion as wars or other humanitarian emergencies, natural disasters can lead many to acquire disability as a result of traumatic events causing anything from limb loss, spinal cord injuries, brain traumas and more [12].

On the other hand, people with disabilities and Disabled People Organisations (DPOs) can provide invaluable resources and expertise which are key to mitigate the negative impact of environmental disasters and promote inclusive reconstruction efforts [22-25,29]. For example, Pertiwi, Llewellyn and Villeneuve [25] examined the implementation of three disability-inclusive preparedness projects led by DPOs in Indonesia. Their findings highlight how, after they took part in a capacity development programme on disaster risk reduction, and received adequate funding for the programmes, DPOs were able to collect relevant data to advocate for policy changes, and work with influential members of local communities to reduce disability stigma. The DPOs were able to work with multiple stakeholders and pool resources with other organisations to implement effective and inclusive community-based disaster risk reduction efforts [25].

Top-down missions, sustainability particularly, run the risk of being confused by nonalignment of definitions. Salkeld [22] in discussing disability and sustainability in relation to UK policy, lays out the implications of 'multiple sustainabilities' in relation to disability inclusion. According to Salked there is 'weak' and 'strong sustainability'. The difference between these two concepts lies in the belief that the capital of natural resources can be substituted by man-made or technological capital-this is weak sustainability. In contrast strong sustainability is the belief that the continuity of the natural resources' capital is essential to the continuity of human life and civilisation [30]. Salkeld explains that there are disablist implications for both ends of the spectrum, which impact disabled people, and create tensions between the priorities of disability equality and the natural environment [22]. Both conceptualizations of sustainability in their current form lack emphasis on the social implications of sustainability in the context of disability. As an alternative to these views, the concept of 'just sustainabilities' allows disability as an issue of social justice to be combined with concern for environmental sustainability [31,32]. Agyeman, Bullard, and Evans [33] conceptualise a 'just sustainability' as 'the need to ensure a better quality of life for all, now and into the future, in a just and equitable manner, whilst living within the limits of supporting ecosystems'.

Recent contributions to ecological economics and related social sciences indicate that issues such as climate change, resource depletion and environmental degradation cannot be effectively addressed under conditions of continued economic growth [34]. Fritz and Koch 2014 [34] discuss the growing body of literature that interprets prosperity 'beyond' economic growth, with ecological sustainability, social inclusion and quality of life being the dimensions of measure. However, to ensure that these balanced prosperities that enable 
ecological sustainability become a reality, the projected 2 billion people in need of AT by 2050 must be both included and accommodated for [2].

\section{Circular Models of AT Provision}

The circular economy (CE) is based on the principles of designing out waste and pollution, keeping products and materials in use, and regenerating natural systems. Value retention is built in at all stages, to reduce the necessity for further finite resource use. The basic principle of CE is that materials and products are reused, remanufactured, repaired and recycled at end of life rather than discarded.

$\mathrm{CE}$ has never been so high on the political agendas of governments as it is right now [35-38]-it is widely acknowledged to promote economic growth by creating new businesses and job opportunities, saving material cost, dampening price volatility, improving the security of supply, while at the same time reducing environmental pressures and impacts [39]. Patwa et al. [40] investigating CE models in an emerging economy context found that there is a strong influence of factors such as consumer behaviour on the acceptance of remanufactured products and using products as a service to encourage the adoption of CE practices in emerging economies-the AT sector may be well placed to accommodate these factors. As well as this, it is important to realise that these approaches are not just about individual business practice, and indeed much potential is lost by looking at the overall solution this way. Fehrer [41] discusses this and promotes an institutional perspective that shows that all business practices are part of larger societal and ecological systems, so that a real transition toward sustainability demands joint institutional alignment processes which balance the adaptive tensions between social mission, environmental stewardship and economic growth.

Putting a circular model into practice in AT is illustrated in Figure 1, with differing appropriate actors overlapping across activities. It can be seen that many elements of CE are highly synergistic with existing AT service delivery in low resource settings, or they already represent a core aspect of AT provision models. Maclachlan et al. [42] state that the adoption of a stronger systems thinking perspective within the assistive technology field should allow for more equitable, more resilient and more sustainable assistive technology across high, middle- and low-income contexts and countries. We propose that increased localisation of the entire loop would be a key enabler of this systems approach.

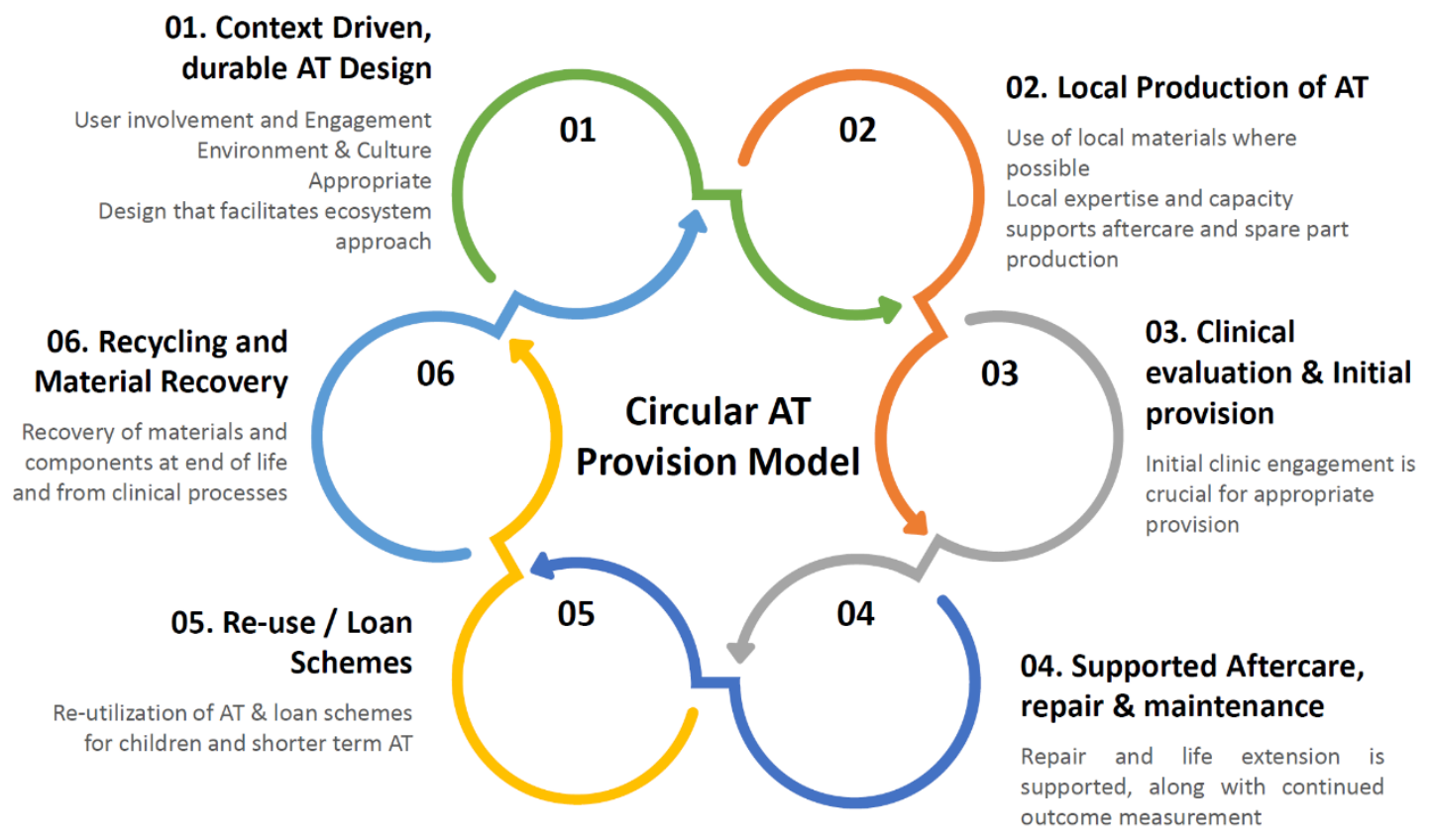

Figure 1. A circular AT provision model. 


\section{Potential Opportunities in a Systems Approach to Local Production of AT}

The concept of localised, distributed manufacture is not new. Prior to the Industrial revolution, products were made locally by artisans and craftspeople, who would mostly use local materials, and they would sell directly to customers, who were known to them. There were no brokers and barely any supply chain, other than for raw materials. If something broke and was fixable, this was usually done by the original maker, who was best placed to do the work. Most of the world has moved very far from this model, and global supply chains dominate most sectors. As a result, a linear model of take-make-dispose is now dominant, i.e., taking materials, making a product, and simply throwing it away when it does not work well, and buying another one. Whether the approach is charity- or profit-led, this is no less true of AT. In wealthy countries this disposable approach to AT does not lead to lack of AT provision, but it is a problem in low-resource settings. Community-based approaches are recognised as a route to better achieve AT access for those in LMICs. Matter et al. [43] completed comprehensive scoping review of assistive technology in 2016 and two of their key findings were that taking a systems approach could help improve access to affordable assistive technologies and that 'community based approaches may be a way to enable underserved groups to access assistive technologies'.

For a wide range of AT, some form of customisation is required if the AT is going to meet the needs of the user. This is best done by a trained clinician or professional who needs to physically assess the patient's needs and prescribe a bespoke solution. For example, the correct sizing and tuning of a wheelchair, the bespoke fabrication of a prosthetic socket for the specific anatomy and use case of a person-'s residual limb, or the examination of a person's eyes and subsequent prescription of appropriate glasses or contact lenses to correct refractive error.

In high resource settings this clinic-patient relationship generally continues beyond fitting or initial prescription, however in low resource settings, AT provision is often conducted in such a manner that there is a disconnect with the user after provision, a lack of outcome tracking and the available follow up services are largely inadequate [44].

In the prosthetics scoping study, multiple participants highlighted the clear need for greater engagement after initial provision, and a lack of both aftercare and repair services. There was a strong desire for more field repairable devices, and the need for innovation in both process and product that address components with a short useful life-socket liners being an example, which wear out quickly, and have a critical impact on the efficacy of the whole prosthesis.

Participants highlighted a need for systems approaches and multi-stakeholder innovation, but recognised the difficulties in pushing these ideas forward. Context specific innovation is needed with adaptable, adjustable designs being developed or desired by participants. This is particularly important in agricultural communities where residual limbs swell and change with the seasons, based on the varying work and diet of the person. This is not so much the case in high income settings, where urban life does not see much seasonal variation in life style. Yet, devices are pretty much all designed for this later context, which limits utility elsewhere.

One participant estimated that a person that is born with a congenital condition requires on average of 25 devices in a lifetime. Therefore, a solution for long term provision is required, yet the stability of the supply of devices does not reflect this, and devices in LMICs are used for far longer than they should be, or simply not at all.

In the eyecare scoping study, many entrepreneurs in the eyecare scoping study commented on the difficulties in "closing the supply chain gap" because of inefficient or inaccessible aspects of the supply chain. In particular, manufacturing processes, logistical barriers and the complex procurement of materials were often discussed by entrepreneurs as barriers to delivering innovation in the area of provision of eyeglasses.

Entrepreneurs noted how limited material options and production capacity often cause supply chain bottlenecks, leading to inaccessible or inefficient supply chain options. 
The impact these barriers have on the supply chain is amplified when business is not limited to national or regional production and delivery.

When delivery is attempted outside of urban settings, into less resourced areas, these supply chain issues are made more difficult as manufacture and distribution involves an increased complexity with the added costs. Rural delivery models are notoriously hard to achieve. These problems could be improved with a local ecosystem around manufacture. Lengthy, complex supply chains for materials and products could be simplified and more of the value creation achieved locally.

\section{AT2030 Case Study: Wazi}

The Ugandan company, Wazi, are being supported through the AT Impact Fund. Wazi have a specific goal of localising eyeglasses frame production within Uganda as currently there is a complete lack of regional manufacture, and all components are imported, mostly from China. These imports come with high taxation and customs duties, as eyeglasses are deemed to be luxury items, increasing the price of these ATs that are a requirement for nearly 2 million people per year in Uganda. This includes both adults and children and takes into account the spectacle replacement rate for different groups.

A lack of local production also means a lack of local design, and for eyeglasses, aesthetic is of high importance, no matter the income setting-it has a significant influence on the stigma associated with visually impairment, which carries more connotations in low resource settings compared to high for various social reasons. It is also important to keep in mind that eyeglasses are a medical device and once frames have the prescription lenses glazed in them, not only does the perceived benefit for them increase, they have the potential to increase someone's productivity and quality of life over a life course [45]. Such small batch, local manufacture is not specific to LMICs, Cubitts in the UK manage this eyeglass manufacturing model while residing in central London where property prices are some of the highest in the world.

If more focus could be placed on building local capacities, i.e., more of the innovation process and production in a local setting then this could have a vital knock-on effect on a number of other poorly functioning aspects of the value chain. Furthering local production and expertise allows product design to be highly context specific, and appropriate for the specific climate. Manufacturing expertise and capacity could directly facilitate formal or semi-formal repair services for AT. Re-use strategies, which reduce costs and increase availability of shorter term AT, for children for example, could be facilitated by manufacturer led refurbishment, and end of life material and component recovery could be achieved efficiently, retaining value in the AT ecosystem. Not only this, but profit where it is made could be building self-sustaining businesses, and not reliant on aid funding. By building local ecosystems, the circular systems approaches are required for sustainable AT provision could be enabled [30].

Local systems approaches do not mean siloed activity, and the advantages of globalisation can still be fully utilised. The international transmission of know-how, knowledge and technological expertise is growing and it is increasingly important in the world economy [31,32]. The systems of distributed manufacturing and design sharing, are changing business models everywhere. An important additional global trend that can facilitate local innovators is the move to shared makerspaces and workshop facilities. These give AT innovators, and if accessible, people with disabilities, the opportunity to prototype devices and develop their ideas in a supported setting, and the number of these are increasing rapidly throughout income settings [46-48].

A particularly important additional result of more distributed manufacturing capabilities across LMICs, is the facilitation of humanitarian response efforts, which are crucial in terms of disability inclusion. Reliance on global supply chains and lack of production close by has long hampered critical disaster response, and for this reason humanitarian groups are moving to encourage distributed manufacturing [49,50]. A humanitarian NGO, Field Ready, uses distributed manufacturing to produce essential non-food items locally 
where they are needed during humanitarian responses [51]. Such supplies can be available to communities in need and to relief workers more quickly. They are often cheaper than alternatives, and provide appropriate solutions to problems, often engaging local people in designing and making necessary items, and supporting economic development [51]. However, scaling up requires local production capabilities-skills, tools, and information such as designs to be boosted by adoption of these methods by aid agencies, international non-governmental organizations (INGOs) and others [51].

The pieces of the puzzle we focus on here are not truly the whole 'system'. Bringing the production ecosystem closer is not enough without financing and distribution in place too. When this is not inherent within government systems such as health coverage, new economic systems around AT will also be required. For example, SME financing for the producer, working capital for the distributor (might be the same person as the producer) and, most definitely, ways of financing the solution for the end user (which could include charitable contributions) will be needed.

To enable localised systems approaches that also take advantage of symbiotic relationships with other sectors, the Innovation Action [52] initiative looks to create mappings of various sectors, so that local ecosystems can be better understood, and potential beneficial relationships can be identified. This project aims to bring together data and understanding from different programmes for future use. Local Production Local Solutions is part of the FCDO COVIDaction Programme which responded to the COVID pandemic by supporting innovators pivoting to healthcare products needed in their local communities. As part of this over 600 producers have been mapped, mainly within Africa. Concurrently on Innovation Action, the AT2030 programme is gathering information about stakeholders working in areas relevant to innovation, disability, and assistive technology in Kenya, with plans to expand this more widely. By housing these maps together, creating a cross-referenceable resource, local manufacturing capacities can be more easily identified. The initiative is also partnered with the Open Know Where Project [53], which aims to allow different mapping initiatives to cooperate more easily with a common data standard. This is guided by the principle that the best way for all of these resources to bring the social good is by working together and compiling unified data on all of the various sectors and specific aims that different organisations have.

Finally, it is important to re-iterate that while we are discussing the potential of more distributed manufacturing capacities to improve overall AT provision-not all AT is suitable for these models. For products and components where requirements are broadly similar across contexts or allow core components with modular adaptation to specific contextual needs, then mass production in singular locations may be the best way forward. Sensitive electronic devices, like those found in many hearing aid central units, may be best manufactured in established clean factories, until there is significant improvement in the complexity and scaled quality that local production ecosystems could provide.

\section{Innovation Opportunity Areas That Could Allow Increased and Sustainable AT Provision}

Assistive products work best when they are matched to the needs and goals of the individual, and the environment in which the activities are or will be performed [54,55]. There is a well-recognised and critical need for much greater context specific innovation for bespoke AT, which is much harder to achieve if the majority of the processes of product development and production are geographically separated. There is huge value in fully understanding outcomes, but with large geographic barriers between stakeholders, the likelihood of extensive user feedback influencing AT design is much less likely, or at least very expensive.

Albala et al. [16] explain that charity-based and globalisation models appear to be the most prominent models in LMICs and dictate how AT are innovated, produced, supplied and experienced by users. They go on to show that current delivery options available within LMICs tend to produce a power relationship whereby LMIC users are reliant on the sporadic willingness of companies and donor agencies to supply AT, often with 
inappropriate fit and poor quality [16]. Smith et al. [54] show that distributing a "onesize fits all" assistive product may result in limited usage, and poor technology adoption. Moreover, the resulting AT provision might not only result in non-use but can actually harm the user or other people in the user's environment and lead to reluctance to try other or additional products $[54,56,57]$.

Bringing more of the product development and production ecosystem closer to users could help address these issues. Pearlman et al. has highlighted a number of technical advances and approaches for design, manufacturing that could increase production in low-income countries [54,58,59].

Durability is another key convergence between what is needed to improve AT product ranges for low resource settings, and what is also essential for sustainable models. The 'planned obsolescence' that has become highly problematic in many consumer products is certainly much less present in AT products, however the unsuitability of many AT designs for the environments faced in LMICs result in the same issue. Durability is a precursor to repair for product life extension, and in general each product life stage should be extended as much as possible before moving to the next in order to prolong total life [60-62].

\subsection{Potential of Digital Fabrication}

Digital fabrication (including additive manufacturing, CNC (computer-numerical control) and lasercutting) are becoming widely available. These are all within the same family of machinery that has already transformed mass production factory line approaches. They focus on 'economies of scope' rather than 'economies of scale'. What used to require a larger set of machines and therefore greater initial capital expenditure to even prototype is much more accessibly costed and sized, and this has a great potential to democratise and localise innovation and subsequent production globally. This accessibility is not only economically inclusive, it is inclusive of people with disabilities, with digitally led processes bringing more access to user-led making [63,64].

There is strong potential for these techniques to change the way many forms of AT are delivered, and for some this is already the case. Much of AT needs individual customisation of components and this is exactly what these methods offer-efficient, digitally led one-off production of parts in accessibly sized machines for a range of scales. This could also ease

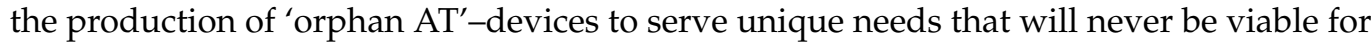
any kind of scale $[65,66]$. As discussed earlier, context specific solution could be developed that take into account specific environmental or cultural challenges.

We will not go into much detail here, but additive manufacturing approaches are already in use or being developed for various AT-wheelchairs [67], hearing aid components [68], extensively in eyeglasses [69-71] with particular use in addressing provision for users with craniofacial abnormalities $[72,73]$, prosthetics $[74,75]$ and orthotics $[76,77]$ as well as many others AT types. Much of this development is current at the research and development stage but work on the service approach in real LMIC settings is lagging.

A double-edged sword is that additive manufacture currently is overwhelmingly dominated by plastic-plastic is a versatile, malleable, shapable material, and this is what allows much of the current abilities of 3D printing, and many other established manufacturing processes. However, evidence of the environmental impact of plastics is becoming more and more bleak. Other materials are available for digital manufacture but currently have higher price tags. Many groups are working on circularising additive manufacturing by recycling printing material [78-81], and this does present high potential for shorter, more resilient supply chains, however there are hurdles to overcome if scale is to be achieved for these approaches.

In P\&O particularly, digital manufacturing is used extensively already. This is a wellresearched area with many commercialised models; however, these primarily reside in high income countries. Dickinson et al. [82] discuss the applicability of these methods to LMIC settings in a recent study. The human-device interfacing component that requires bespoke 
construction, is already usually made locally, but usually using non-digital methods. Digital methods could address the lack of provision in LMICs which results in only 5-15\% of amputees in LMICs having access to a prosthesis $[83,84]$. They promise to optimise the available clinical resources, however the truth of this claim is currently difficult to assess, as the production chain and variables involved are complex [85].

Centralised models, likely placed in capital cities or major urban centres, are 'more local' than overseas manufacture, and offer advantages to AT clinics, such as specialist manufacturing expertise, trained staff, and much better potential for quality assurances [54]. Centralised models also open up the potential for 'one stop shop' models of AT production, with multiple AT types using the same service, taking advantage of the overlapping knowledge sets of devices, and creating a more scalable, stable business model. This approach could allow the integration of circular strategies through product life extension facilitation in the form of regional access to expertise and spare parts and material recovery through engagement with the network of AT clinics they could be involved with.

Another opportunity of is that digital product development flows lend themselves very well to non-local expertise involvement, which is a key reason why digital techniques are at the forefront of distributed manufacturing strategies [86]. Designs can be shared globally, and modified to suit specific requirements. This takes advantage of globalisation, while building the capacity and economic benefits in a localised setting-i.e., the now famous adage 'Think globally, act locally', introduced in 1915 by the Scottish planner and conservationist, Patrick Geddes [87,88]. Assistive technology design sharing is well underway with multiple websites either dedicated to it, or have large relevant sections $[89,90]$.

Major challenges remain, however. The produced pieces still require finishing and post-processing (for instance, heat treatment) to achieve functional tolerances and performance targets. Many sectors are still addressing how 3D printed parts will be assessed for quality, as there is high variation between machines, environment and indeed from part-to part, with strength concerns due to the layer-by-layer construction. These issues are forcing many to rethink methods for inspection and testing, particularly when only a single custom part is needed [86]. It must also be kept in mind that once scale of any specific geometry of product or component that is required goes above a certain level, then these methods are not an efficient way in which to produce mature designs, and other more established manufacturing techniques are best suited.

\subsection{Repair of $A T$}

While end of life approaches to reduced environmental impact such as recycling have been widespread across the world for some time, the developed world is rediscovering the importance of extending product life cycles as a route to improved sustainability. In LMICs, the informal repair economy has always been highly present, as people simply cannot afford to just replace products. For instance, there is a strong role that could be played by the Juakali within Africa - the high prevalence of micro SMEs (MSMEs) and the skills developed within these are well suited to further amplify a repair economy with greater links with other sectors. High income countries are only now realising the benefits both to local economies and to the environment of repair, with the European Commission and the UK recently bringing in Right to Repair regulations on a range of key products [91].

From our analysis of multiple studies conducted by AT2030 and partners in Uganda, Sierra Leone, Indonesia and Kenya (submitted to Disability \& Society journal) we found that the majority of the useful life of AT is achieved via repair and maintenance. However, this is commonly not achieved as part of the provision model of the original supplier of the AT. In Lower- and Middle-Income Countries (LMICs), AT provision is often conducted in such a manner that there is a disconnect with the user after provision, a lack of outcome tracking with few follow up services [44]. Repair is achieved either by the user or via a third party, which is usually an informal, non-specialist tradesperson. This informality is not necessarily bad, informal strategies, if facilitated appropriately bring together user 
empowerment, capacity building and take advantage of present strengths of low resource settings, rather than trying to impose new systems on communities.

For many AT though, specialist skills are necessary, and while specialist repair services exist, UNICEF found that in developing countries $28 \%$ of respondents reported that specialist repair services were not available and $47 \%$ reported that only limited repair services were available [1]. Only a minority (25\%) reported that these repair services were available, this compares to the $62 \%$ in high income countries [2].

With increased localisation of AT production, a key advantage would be that the crucial repair services for AT could be more easily enabled. With manufacture of devices being closer to the user, as well as allowing context specific designs and further user engagement, the expertise of the original producers could be leveraged in creating better repair services. This could take the form of product-service models of business, where the original company not only provides the initial product but has a continued relationship with the user and provides the continued maintenance of the device [92].

An additional advantage of local manufacturing in relation to repair is that spare parts can be supplied much more effectively. The WHO states that assistive products are often manufactured using parts that are not replaceable locally, for example, hearing aid batteries and wheelchair tyres. This contributes to high abandonment rates. To achieve equitable access, assistive products need to be manufactured with parts that can be repaired, maintained and replaced locally (Director General WHO, 2017).

Even if original devices are indeed shipped in from overseas, an increase in local specialist production capacities could enable local spare part production, which is being explored by multiple groups from other sectors using digital manufacture such as 3D printing [93-96]. This could still be facilitated by original AT suppliers with the sharing of digital blueprints of parts. This does not have to rely on advanced manufacturing techniques as, unlike in most high-income settings the general informal repair economy is a thriving area in LMICs. However, informed schematics and guidance from AT product designers would greatly increase the effectiveness of this part of the value chain.

No matter the specific model, repair instructions for AT would amplify the availability of quality repair of AT, potentially leading to reduced environmental impact of devices, but more importantly increased value to the AT user. This would have a knock-on effect on the efficacy of AT provision, as a mistrust of poor repairs and a lack of faith in the continued access to AT was cited by users in our above studies as highly detrimental to their AT experience. This lack of trust in provision has also been well documented elsewhere to be highly detrimental to engagement of both current and potential beneficiaries of AT [57]. What is key is to recognise the inevitability of AT repair and therefore to design AT for repair.

\subsection{Reuse Strategies}

Reuse strategies are a key part of sustainable, circular approaches, generally being labelled as the top three ' $R$ 's along with Reduce and Recycle. In general, the concept of Reuse refers to the repeated utilization of materials, parts or finished products by multiple users. However, different definitions of circular economy might offer different interpretations or complementary conceptualizations [97].

The idea of Reuse of AT is not new. The argument is that reused AT is less expensive than new, for whoever is paying-be it a health service, charity or user or a combination of these. Reuse represents a common model of AT provision implemented by many charities operating in low resource settings [98]. The reasoning behind this model is that donated devices could be refurbished and be effective for individuals who might otherwise be unable to access AT through other forms of provision [57]. On the other hand, many of these donated devices are of low quality, not appropriate to the context of use and fail to match the needs of users [98]. The inherent risk of providing devices that users are dissatisfied with is that many will simply be abandoned, also contributing to the increase in waste rather than reducing it, but also building up of distrust in AT as an option [57,99]. 
However, AT reuse schemes are not necessarily only implemented in LMICs. For example, Kniskern, Philips and Patterson reports the presence of several community-based reuse programmes of AT that have been active in the US since 1984 [100]. The Association of Assistive Technology Act Programs (ATAP) even developed a reporting protocol that can be used to collect data about AT reuse at a national level and estimate the total value of reused devices. As part of the development of the reporting tool they distinguish two type of reuse. The first one being linked to exchange activities of AT between users and the latter as a result of refurbishment/repair/recycling activities that are usually mediated by third sector organizations [100].

Fundamental to the success of AT reuse programmes is adequate monitoring of the outcome and impact of the devices provided to new users. A positive example of this is the Paraquad community-based programme affiliated with the School of Occupational Therapy at Washington University [101]. As part of this programme, providers carry out follow-up evaluations after three to six months using surveys to assess the changes that reused AT cause in both functional performance and inclusion in community activities [101].

Another form of AT reuse are loaning schemes that are common for providers of paediatric AT. Because of their fast changing abilities associated with growth and development, children often need to use ATs for only limited periods of time. Even if their need for AT remains somehow consistent, their physical growth means that devices will need to be changed to accommodate growth [102]. Reuse programmes provide children and families with easier access to a variety for different loaned ATs ranging from wheelchairs to communication boards, feeding aids to devices for environmental control. Although the practice of AT reuse for children was found to be both common and effective, most reuse happens only within a single programme carried out by an individual organisation, which limits the reach and capacity of these practices [102].

A highly successful example of AT loaning and reuse scheme implemented at national level is the Norwegian Assistive Technology Provision Model [103]. Through the 18 AT centres established around the country, people with disabilities in Norway can be assessed and provided with AT devices that will be loaned to them for as long as they need them [103]. Once the user has no more need for the AT device it can be returned to the same centre which will proceed to repair and refurbish it before loaning it to another potential user [104]. Thanks to the effectiveness of this scheme, approximately a third of AT devices provided in Norway are actually reused [104]. Ultimately, reuse of AT has huge potential to cut costs and improve the sustainability of AT provision, but it can only be effective if there is a strong commitment to ensure that AT for reuse is of good quality and appropriately match the needs of users and their context.

\subsection{Material Efficiency and Recovery from AT}

Consumption is at the heart of the climate crisis, and ways to reduce material consumption will contribute to a reduction in human caused impacts. Overall useful product life extension is crucial, but outside of this, product and process innovation that continues to retain value in material resources is beneficial. This value retention in resources is not only good for the environment but means less requirement for external value input, and ultimately this could trickle down into more reliable provision for users.

\section{AT2030 Case Study: Amparo}

Frequent socket replacement is especially common in the earliest stages of becoming a prosthesis wearer, as the residual limb shrinks and stabilises over the first few years of prosthesis wear [105]. Prosthetic service delivery models, therefore, need to be set up for the initial prescription process, and the continued needs of maintenance and adaption. In LMICs, scarce resources, limited-service delivery locations and a lack of trained experts make the delivery and continued maintenance of prosthetics challenging. [106,107]

Amparo's leading innovation is a mouldable prosthetic socket which prosthetists can reshape multiple times to fit a wearer's residual limbs as they naturally change shape. 
Additionally, the socket is not fitted using the traditional plaster-casting method, it uses a novel direct to limb vacuum moulding technique.

While addressing the user requirements was primary for the Amparo team, the potential for increased environmental sustainability through better material efficiency is significant for the approach they have taken. Not only does their fitting process remove the material usage during the plaster casting process and prototyping, but the continued reshapability means the same socket replaces multiple discarded sockets over the first few years of a user's journey through rehabilitation. There is also a high degree of reduction in overall machinery requirements meaning less footprint associated with upkeep and eventual replacement.

Another example is the use of highly recyclable polymers in AT design such as polypropylene. In the $\mathrm{P} \& \mathrm{O}$ scoping study we spoke to a clinic in Cambodia who have been recovering polypropylene from the fabrication process, and used sockets for some time. They re-process the material where possible to make new sockets [108]. Further exploration and research is needed to identify where material recovery could be better achieved.

An advantage with the prosthetic sockets mentioned above, which holds true for a range of components across prosthetics and orthotic braces, is that they are often a single material. This makes material recovery strategies easier to achieve, although more and more high-end devices may be composites such as carbon fibre reinforced polymers which limit recovery. More complex assistive devices, particularly those containing electronics are a harder problem to solve, both in regard to reuse and material recovery. They may represent a significant environmental impact however, with a range of materials used paired with low useful life span. If devices had end of life considerations built into the original design, then they could be better planned for. These considerations often go hand in hand with design for repair and reuse, for example modularity, which often increases both upgradability and component breakdown.

\section{Conclusions}

\subsection{What Needs to Be Done?}

While we have laid out the potential opportunities in these approaches, there is much that would need to happen to make them possible, and there is a great deal of complexity in the necessary actions. The following actions are neither exhaustive, nor complete, but act as a starting point for discussion.

Governments and funders can help tilt the playing field towards local production-led innovation by the provision of tax breaks, grants or other financial incentives. They could also look to provide locally produced devices, perhaps helping to co-locate production sites near to hospitals and within community sites and programmes. This would help to drive demand, whilst also producing local employment. The building of local capacity and skills would also be needed and the training that this requires would not be a quick process.

Current importers, who, in LMICs are often not the government but NGOs would need to be persuaded to work together and shift from the centralised manufacturing and import model to a localised production model or at least find a balance between the two. This requires research into what works, what is appropriate where.

A full scoping of the current barriers to local production models, particularly addressing issues around actual and perceived quality is needed. For example, access to quality assessment and testing facilities is currently a barrier faced by many medically oriented innovators in LMICs-in Africa particularly, there is a total lack of these services.

The answers to some of the questions that are outstanding may already be available, but require increased communication between government, funders, NGOs, academic groups, industries that focus their attention on specific separate mission-led arenas. This obviously refers to disability inclusion and sustainability, but this is not exclusive. 


\subsection{Concluding Summary and Final Remarks}

The disruption of supply chains globally due to COVID-19 has shone a light on the problems of the globalised model of manufacturing for essential items such as AT. This does however bring potential in the recovery period from the pandemic as a time to re-assess the monopoly that this model has. While these global supply chains are an important part of the puzzle, allowing cheap prices for some products through economies of scale, we have illustrated some localised approaches that could offer the missing pieces that AT ecosystems need to improve and allow trustworthy and robust access to devices.

Interestingly there are multiple synergies between what improvements are needed within AT provision and the wider environmental issues in the SDGs, which suggest AT could be particularly suited to pave the way for the sustainable local models that are needed in other industries.

To summarise these ideas:

- People with disabilities are particularly vulnerable to the negative effects of climate change, which will also likely exacerbate the difficulties of AT provision globally.

- Localised models of AT production could increase user and context specific AT innovations, while concurrently enabling circular approaches that reduce their environmental impact as well as bringing economic benefit to local communities.

- Localised models of AT could enable the potential of much needed service aspects of AT provision such as reuse and repair-increasing stable, reliable access to devices, and prolonging the useful life of products, and reduce the environmental impact of AT.

- $\quad$ AT needs to be designed with end of life in mind, this means designing for a system where the materials and components can easily be recovered and recirculated to the local points of production.

- Resilient, stable, and importantly equitable access to AT are an imperative and will become more so as climate change intensifies. The circular approaches we have outlined in this paper are the foundation of a systems approach to reducing the impact of climate change while increasing AT provision.

Author Contributions: Conceptualization, B.O., G.B., T.G., C.H. and M.M.; writing—original draft preparation, B.O., G.B., P.M., J.M., T.G.; writing-review and editing, B.O., P.M., T.G., C.H. and M.M.; funding acquisition, M.M, C.H. All authors have read and agreed to the published version of the manuscript.

Funding: This research was funded by Foreign, Commonwealth and Development Office (FCDO, formerly Department for International Development (DFID)), grant number GB-GOV-1-300815 Award date: 28 January 2019.

Institutional Review Board Statement: UCL Research Ethics Committee (1106/014). Data werecollected under the UCL Data Protection policy (project registration number: Z6364106/2019/01/08.

Informed Consent Statement: Informed consent was obtained from all subjects involved in the studies outlined in the paper.

Data Availability Statement: Data available on request due to restrictions. The data presented in these studies are available on request from the corresponding author. The data are not publicly available due to confidentiality.

Acknowledgments: The authors would like to acknowledge all the partners on the AT2030 Programme (especially the Clinton Health Access Initiative and AT Impact Fund colleagues), as well as colleagues whose discussions have contributed to the thinking within this paper.

Conflicts of Interest: The authors declare no conflict of interest. The funders had no role in the design of the study; in the collection, analyses, or interpretation of data; in the writing of the manuscript, or in the decision to publish the results. 


\section{References}

1. World Health Organisation. Assistive Technology. Available online: https://www.who.int/news-room/fact-sheets/detail/ assistive-technology (accessed on 6 September 2021).

2. Rohwerder, B. Assistive Technologies in Developing Countries; Institute of Development Studies: Brighton, UK, 2018.

3. Bringezu, S.; Arden Clarke, C.; Fischer-Kowalski, M.; Graedel, T.; Hajer, M.; Hashimoto, S.; Hatfield-Dodds, S.; Havlik, P.; Hertwich, E.; Ingram, J.; et al. Resource Efficiency: Potential and Economic Implications, A Report by the International Resource Panel Report; International Resource Panel: Paris, France, 2017; ISBN 9789280736458.

4. Kejariwal, R.; Kobayashi, E.; Savage, M.; Seghers, F.; Bhosa, T. Product Narrative: Hearing Aids, AT2030 Programme \& ATscale Global Partnership for Assistive Technology. 2019. Available online: https://at2030.org/pn-hearing-aids/ (accessed on 15 July 2021).

5. Chaudron, M.; Savage, M.; Seghers, F. Product Narrative: Eyeglasses, AT2030 Programme \& ATscale Global Partnership for Assistive Technology. 2020. Available online: https:/ / at2030.org/pn-eyeglasses / (accessed on 15 July 2021).

6. Vieira, C.M.; Franco, O.H.; Restrepo, C.G.; Abel, T. COVID-19: The Forgotten Priorities of the Pandemic. Maturitas 2020, 136, 38-41. [CrossRef]

7. Smith, E.M.; Toro Hernandez, M.L.; Ebuenyi, I.D.; Syurina, E.V.; Barbareschi, G.; Best, K.L.; Danemayer, J.; Oldfrey, B.; Ibrahim, N.; Holloway, C.; et al. Assistive Technology Use and Provision During COVID-19: Results From a Rapid Global Survey. Int. J. Health Policy Manag. 2020, 2020, 1-10. [CrossRef]

8. Ebuenyi, I.D.; Smith, E.M.; Holloway, C.; Jensen, R.; D'Arino, L.; MacLachlan, M. COVID-19 as Social Disability: The Opportunity of Social Empathy for Empowerment. BMJ Glob. Health 2020, 5, 3039. [CrossRef]

9. Tebbutt, E.; Brodmann, R.; Borg, J.; MacLachlan, M.; Khasnabis, C.; Horvath, R. Assistive Products and the Sustainable Development Goals (SDGs). Glob. Health 2016, 12, 79. [CrossRef] [PubMed]

10. Nilsson, M.; Griggs, D.; Visbeck, M. Policy: Map the Interactions Between Sustainable Development Goals. Nature 2016, 534, 320-322. [CrossRef] [PubMed]

11. World Health Organization. World Report on Disability. 2011. Available online: https://apps.who.int/iris/handle/10665/44575 (accessed on 25 September 2021).

12. Ito, A. Crises, Conflict and Disability: Ensuring Equality; Routledge: Abingdon, UK, 2015; ISBN 9781138960305.

13. Khavul, S.; Bruton, G.D. Harnessing Innovation for Change: Sustainability and Poverty in Developing Countries. J. Manag. Stud. 2013, 50, 285-306. [CrossRef]

14. Karlan, D.; Appel, J. More Than Good Intentions: Improving the Ways the World's Poor Borrow, Save, Farm, Learn, And Stay Healthy; Plume: New York, NY, USA, 2012; ISBN 9780452297562.

15. Danemayer, J.; Boggs, D.; Smith, E.M.; Delgado Ramos, V.; Battistella, L.; Polack, S.; Holloway, C. Indicating Assistive Technology Supply \& Demand. Assist. Technol. J. Rehabil. Eng. Assist. Technol. Soc. N. Am.. (pending publication).

16. Albala, S.; Holloway, C.; Austin, V.; Kattel, R. New Economics of Assistive Technology: A Call for a Missions Approach. Available online: https: / / www.ucl.ac.uk/bartlett/public-purpose/publications/working-papers (accessed on 9 July 2021).

17. Liao, C.; Seghers, F.; Savage, M. Product Narrative: Prostheses, AT2030 Programme \& ATscale Global Partnership for Assistive Technology. 2020. Available online: https:/ / at2030.org/pn-prostheses/ (accessed on 16 July 2021).

18. Mörchen, M.; Ocasiones, E.; Relator, R.; Lewis, D. Climate Change, Vulnerability, and Disability: Do We "Leave No One Behind"? Disaster Med. Public Health Prep. 2020, 1-2. [CrossRef] [PubMed]

19. Wolbring, G.; Leopatra, V. Climate Change, Water, Sanitation and Energy Insecurity: Invisibility of People with Disabilities. Can. J. Disabil. Stud. 2012, 1, 66. [CrossRef]

20. Gaskin, C.J.; Taylor, D.; Kinnear, S.; Mann, J.; Hillman, W.; Moran, M. Factors Associated with the Climate Change Vulnerability and the Adaptive Capacity of People with Disability: A Systematic Review. Weather Clim. Soc. 2017, 9, 801-814. [CrossRef]

21. Wolbring, G. A Culture of Neglect: Climate Discourse and Disabled People. Media Cult. J. 2009, 12. [CrossRef]

22. Fenney Salkeld, D. Sustainable Lifestyles for All? Disability Equality, Sustainability and the Limitations of Current UK Policy. Disabil. Soc. 2016, 31, 447-464. [CrossRef]

23. Abbott, D.; Porter, S. Environmental Hazard and Disabled People: From Vulnerable to Expert to Interconnected. Disabil. Soc. 2013, 28, 839-852. [CrossRef]

24. Bell, S.L.; Tabe, T.; Bell, S. Seeking a Disability Lens within Climate Change Migration Discourses, Policies and Practices. Disabil. Soc. 2020, 35, 682-687. [CrossRef]

25. Pertiwi, P.; Llewellyn, G.; Villeneuve, M. People with Disabilities as Key Actors in Community-based Disaster Risk Reduction. Disabil. Soc. 2019, 34, 1419-1444. [CrossRef]

26. Otto, I.M.; Reckien, D.; Reyer, C.P.O.; Marcus, R.; Le Masson, V.; Jones, L.; Norton, A.; Serdeczny, O. Social Vulnerability to Climate Change: A Review of Concepts and Evidence. Reg. Environ. Chang. 2017, 17, 1651-1662. [CrossRef]

27. Biyanwila, J. Poverty and disability in the Global South. Third World Q. 2011, 32, 1537-1540. [CrossRef]

28. Groce, N.; Kett, M.; Lang, R.; Trani, J.F. Disability and Poverty: The Need for a More Nuanced Understanding of Implications for Development Policy and Practice. Third World Q. 2011, 32, 1493-1513. [CrossRef]

29. Priestley, M.; Hemingway, L. Disability and Disaster Recovery: A Tale of Two Cities? J. Soc. Work Disabil. Rehabil. 2006, 5, 23-42. [CrossRef] 
30. Neumayer, E. Weak Versus Strong Sustainability: Exploring the Limits of Two Opposing Paradigms, 3rd ed.; Edward Elgar: Cheltenham, UK, 2010; ISBN 9781849805438.

31. Agyeman, J.; Evans, T. Toward Just Sustainability in Urban Communities: Building Equity Rights with Sustainable Solutions. Ann. Am. Acad. Pol. Soc. Sci. 2003, 590, 35-53. [CrossRef]

32. Agyeman, J. Toward a 'Just' Sustainability? Continuum 2008, 22, 751-756. [CrossRef]

33. Agyeman, J.; Bullard, R.D.; Evans, B. Just Sustainabilities: Development in an Unequal World; MIT Press: Cambridge, MA, USA, 2003; Volume 29, ISBN 9780262511315.

34. Fritz, M.; Koch, M. Potentials for Prosperity Without Growth: Ecological Sustainability, Social Inclusion and the Quality of Life in 38 Countries. Ecol. Econ. 2014, 108, 191-199. [CrossRef]

35. European Commission. EUR-Lex-52015DC0614-EN-EUR-Lex. Available online: https://eur-lex.europa.eu/legal-content/ EN/TXT/?uri=CELEX\%3A52015DC0614 (accessed on 14 July 2021).

36. European Commission. Towards a Circular Economy: A Zero Waste Programme for Europe DG Environment. Available online: http:/ / ec.europa.eu/europe2020/public- (accessed on 14 July 2021).

37. European Commission. Development of Guidance on Extended Producer Responsibility (EPR) Final Report. Available online: https:/ / ec.europa.eu/environment/archives/waste/eu_guidance/pdf/Guidance\%20on\%20EPR\%20-\%20Final\%20Report. pdf (accessed on 25 September 2021).

38. Pesce, M.; Tamai, I.; Guo, D.; Critto, A.; Brombal, D.; Wang, X.; Cheng, H.; Marcomini, A. Circular Economy in China: Translating Principles into Practice. Sustainability 2020, 12, 832. [CrossRef]

39. Ellen Macarthur Foundation. Towards the Circular Economy: Economic and Business Rationale for an Accelerated Transition. Available online: https: / / ellenmacarthurfoundation.org/towards-the-circular-economy-vol-1-an-economic-and-businessrationale-for-an (accessed on 11 July 2021).

40. Patwa, N.; Sivarajah, U.; Seetharaman, A.; Sarkar, S.; Maiti, K.; Hingorani, K. Towards a Circular Economy: An Emerging Economies Context. J. Bus. Res. 2021, 122, 725-735. [CrossRef]

41. Fehrer, J.A.; Wieland, H. A Systemic Logic for Circular Business Models. J. Bus. Res. 2021, 125, 609-620. [CrossRef]

42. MacLachlan, M.; Scherer, M.J. Systems Thinking for Assistive Technology: A Commentary on the GREAT Summit. Disabil. Rehabil. Assist. Technol. 2018, 13, 492-496. [CrossRef]

43. Matter, R.; Harniss, M.; Oderud, T.; Borg, J.; Eide, A.H. Assistive Technology in Resource-Limited Environments: A Scoping Review. Disabil. Rehabil. Assist. Technol. 2017, 12, 105-114. [CrossRef] [PubMed]

44. McSweeney, E.; Gowran, R.J. Wheelchair Service Provision Education and Training in Low and Lower Middle Income Countries: A Scoping Review. Disabil. Rehabil. Assist. Technol. 2019, 14, 33-45. [CrossRef]

45. Burton, M.J.; Ramke, J.; Marques, A.P.; Bourne, R.R.A.; Congdon, N.; Jones, I.; Ah Tong, B.A.M.; Arunga, S.; Bachani, D.; Bascaran, C.; et al. The Lancet Global Health Commission on Global Eye Health: Vision Beyond 2020. Lancet Glob. Health 2021, 9, e489-e551. [CrossRef]

46. Steele, K.; Steele, K.; Blaser, B.; Cakmak, M. Accessible Making: Designing Makerspaces for Accessibility. Int. J. Des. Learn. 2018, 9, 114-121. [CrossRef]

47. Prendeville, S.; Hartung, G.; Brass, C.; Purvis, E.; Hall, A. Circular Makerspaces: The Founder's View. Int. J. Sustain. Eng. 2017, 10, 272-288. [CrossRef]

48. Prendeville, S.; Hartung, G.; Purvis, E.; Brass, C.; Hall, A. Makespaces: From Redistributed Manufacturing to a Circular Economy. In Proceedings of the International Conference on Sustainable Design and Manufacturing, Heraklion, Greece, 4-6 April 2016; Volume 52, pp. 577-588.

49. Distributed Manufacturing in Humanitarian Logistics Operations. Emerald Publishing. Available online: https://www. emeraldgrouppublishing.com/archived/products/journals/call_for_papers.htm\%3Fid\%3D8083 (accessed on 15 July 2021).

50. Corsini, L.; Aranda-Jan, C.B.; Moultrie, J. The Impact of 3D Printing on the Humanitarian Supply Chain. Prod. Plan. Control 2020, 1-13. [CrossRef]

51. James, L. Opportunities and Challenges of Distributed Manufacturing for Humanitarian Response. In Proceedings of the GHTC 2017-IEEE Global Humanitarian Technology Conference, San Jose, CA, USA, 19-22 October 2017; Institute of Electrical and Electronics Engineers Inc.: Piscataway, NJ, USA, 2017; Volume 2017, pp. 1-9.

52. Innovation Action. Available online: https:/ / www.innovationaction.org/ (accessed on 15 July 2021).

53. Open Know-Where. Available online: https:/ / www.internetofproduction.org/open-know-where (accessed on 15 July 2021).

54. Smith, R.O.; Scherer, M.J.; Cooper, R.; Bell, D.; Hobbs, D.A.; Pettersson, C.; Seymour, N.; Borg, J.; Johnson, M.J.; Lane, J.P.; et al. Assistive Technology Products: A Position Paper from the First Global Research, Innovation, and Education on Assistive Technology (GREAT) Summit. Disabil. Rehabil. Assist. Technol. 2018, 13, 473-485. [CrossRef] [PubMed]

55. Scherer, M.J. Technology Adoption, Acceptance, Satisfaction and Benefit: Integrating Various Assistive Technology Outcomes. Disabil. Rehabil. Assist. Technol. 2017, 12, 1-2. [CrossRef]

56. Scherer, M.J.; Craddock, G. Matching Person \& Technology (MPT) Assessment Process. Technol. Disabil. 2002, 14, 125-131. [CrossRef]

57. Visagie, S.; Mlambo, T.; Van der Veen, J.; Nhunzvi, C.; Tigere, D.; Scheffler, E. Is Any Wheelchair Better than No Wheelchair? A Zimbabwean perspective. Afr. J. Disabil. 2015, 4, 1-10. [CrossRef] 
58. Jefferds, A.N.; Pearlman, J.L.; Wee, J.; Cooper, R.A. International Mobility Technology Research: A Delphi Study to Identify Challenges and Compensatory Strategies. Assist. Technol. 2011, 23, 232-242. [CrossRef]

59. Pearlman, J.; Cooper, R.A.; Zipfel, E.; Cooper, R.; McCartney, M. Towards the Development of an Effective Technology Transfer Model of Wheelchairs to Developing Countries. Disabil. Rehabil. Assist. Technol. 2006, 1, 103-110. [CrossRef]

60. Tecchio, P.; McAlister, C.; Mathieux, F.; Ardente, F. In Search of Standards to Support Circularity in Product Policies: A Systematic Approach. J. Clean. Prod. 2017, 168, 1533-1546. [CrossRef]

61. Mesa, J.; González-Quiroga, A.; Maury, H. Developing an Indicator for Material Selection Based on Durability and Environmental Footprint: A Circular Economy Perspective. Resour. Conserv. Recycl. 2020, 160, 104887. [CrossRef]

62. Corona, B.; Shen, L.; Reike, D.; Carreón, J.R.; Worrell, E. Towards Sustainable Development through the Circular EconomyA Review and Critical Assessment on Current Circularity Metrics. Resour. Conserv. Recycl. 2019, 151, 104498. [CrossRef]

63. Hurst, A.; Kane, S. Making "Making” Accessible. In Proceedings of the 12th International Conference on Interaction Design and Children, New York, NY, USA, 24-27 June 2013.

64. Thorsen, R.; Bortot, F.; Caracciolo, A. From Patient to Maker-A Case Study of Co-Designing an Assistive Device using 3D Printing. Assist. Technol. 2019, 1-7. [CrossRef] [PubMed]

65. Barbareschi, G.; Holloway, C.S.M.; Sprigle, S. Assistive Technology Design Courses: The Mutually Beneficial Relationship between Engineering Education and the Provision of Orphan Devices; Rehabilitation Engineering and Assistive Technology Society of North America (RESNA): Rosslyn, VA, USA, 2017.

66. Seelman, K.D. Universal Design and Orphan Technology: Do We Need Both? Disabil. Stud. Q. 2005, 25. [CrossRef]

67. Barbareschi, G.; Daymond, S.; Honeywill, J.; Singh, A.; Noble, D.; Mbugua, N.N.; Harris, I.; Austin, V.; Holloway, C. Value Beyond Function: Analyzing the Perception of Wheelchair Innovations in Kenya. In Proceedings of the ASSETS 2020-22nd International ACM SIGACCESS Conference on Computers and Accessibility, Athens, Greece, 26-28 October 2020; Association for Computing Machinery, Inc.: New York, NY, USA, 2020.

68. Alifui-Segbaya, F.; George, R. Biocompatibility of 3d-Printed Methacrylate for Hearing Devices. Inventions 2018, 3, 52. [CrossRef]

69. Ayyildiz, O. Customised Spectacles Using 3-D Printing Technology. Clin. Exp. Optom. 2018, 101, 747-751. [CrossRef]

70. Lee, L.; Burnett, A.M.; Panos, J.G.; Paudel, P.; Keys, D.; Ansari, H.M.; Yu, M. 3-D Printed Spectacles: Potential, Challenges and the Future. Clin. Exp. Optom. 2020, 103, 590-596. [CrossRef]

71. Altinkurt, E.; Ceylan, N.A.; Altunoglu, U.; Turgut, G.T. Manufacture of Custom-Made Spectacles using Three-Dimensional Printing Technology. Clin. Exp. Optom. 2020, 103, 902-904. [CrossRef]

72. Brodie, F.L.; Nattagh, K.; Shah, V.; Swarnakar, V.; Lin, S.; Kelil, T.; Gillan, D.; Romero, D.; de Alba Campomanes, A.G. Computed Tomography-Based 3D Modeling to Provide Custom 3D-Printed Glasses for Children with Craniofacial Abnormalities. J. AAPOS 2019, 23, 165-167.e1. [CrossRef]

73. Novel Use of iPhone Based 3D Face Scanning to Develop Custom 3D Printed Spectacles For Children With Craniofacial Malformations. IOVS ARVO Journals. Available online: https: / /iovs.arvojournals.org/article.aspx?articleid=2767376 (accessed on 11 July 2021).

74. Koprnicky, J.; Šafka, J.; Ackermann, M. Using of 3D Printing Technology in Low Cost Prosthetics. Mater. Sci. Forum 2018, 919, 199-206. [CrossRef]

75. Pourfarzaneh, A.; Taghavi, M.; Helps, T.; Rossiter, J. Towards Adaptive Prosthetic Sockets using 3d-Printed Variable-Stiffness Shape-Memory Structures. In Proceedings of the RoboSoft 2019-2019 IEEE International Conference on Soft Robotics, Seoul, Korea, 14-18 April 2019; Institute of Electrical and Electronics Engineers Inc.: Piscataway, NJ, USA, 2019; pp. 410-415.

76. Banga, H.K.; Kumar, P.; Kumar, H. Utilization of Additive Manufacturing in Orthotics and Prosthetic Devices Development. In Proceedings of the IOP Conference Series: Materials Science and Engineering, Chandigarh, India, 28-30 August 2020; IOP Publishing Ltd.: Chandigarh, India, 2021; Volume 1033, p. 012083.

77. Chae, D.S.; Kim, D.H.; Kang, K.Y.; Kim, D.Y.; Park, S.W.; Park, S.J.; Kim, J.H. The Functional Effect of 3D-Printing Individualized Orthosis for Patients with Peripheral Nerve Injuries: Three Case Reports. Medicine 2020, 99, e19791. [CrossRef]

78. Zhong, S.; Pearce, J.M. Tightening the Loop on the Circular Economy: Coupled Distributed Recycling and Manufacturing with Recyclebot and RepRap 3-D Printing. Resour. Conserv. Recycl. 2018, 128, 48-58. [CrossRef]

79. Sun, L.; Wang, Y.; Hua, G.; Cheng, T.C.E.; Dong, J. Virgin or Recycled? Optimal Pricing of 3D Printing Platform and Material Suppliers in a Closed-Loop Competitive Circular Supply Chain. Resour. Conserv. Recycl. 2020, 162, 105035. [CrossRef]

80. DePalma, K.; Walluk, M.R.; Murtaugh, A.; Hilton, J.; McConky, S.; Hilton, B. Assessment of 3D Printing using Fused Deposition Modeling and Selective Laser Sintering for a Circular Economy. J. Clean. Prod. 2020, 264, 121567. [CrossRef]

81. Garmulewicz, A.; Holweg, M.; Veldhuis, H.; Yang, A. Disruptive Technology as an Enabler of the Circular Economy: What Potential Does 3D Printing Hold? Calif. Manage. Rev. 2018, 60, 112-132. [CrossRef]

82. Dickinson, A.; Donovan-Hall, M.; Kheng, S.; Wiegand, S.; Wills, G.; Ostler, C.; Srors, S.; Tech, A.; Granat, M.; Kenney, L.; et al Technologies to Enhance Quality and Access to Prosthetics \& Orthotics: The Importance of a Multidisciplinary, User-Centred Approach. Glob. Rep. Assist. Technol. Consult. 2019, 22-23. [CrossRef]

83. Campbell, A.I.; Sexton, S.; Schaschke, C.J.; Kinsman, H.; McLaughlin, B.; Boyle, M. Prosthetic Limb Sockets from Plant-Based Composite Materials. Prosthet. Orthot. Int. 2012, 36, 181-189. [CrossRef]

84. World Health Organization. WHO Standards for Prosthetics and Orthotics. Available online: http://apps.who.int/bookorders (accessed on 13 July 2021). 
85. Oldfrey, B.; Miodownik, M.; Barbareschi, G.; Williams, R.; Holloway, C. Digital Fabrication of Lower Limb Prosthetic Sockets. AT2030 Programme. Available online: https://at2030.org/digital-fabrication-of-lower-limb-prosthetic-sockets / (accessed on 9 July 2021).

86. Petrick, I.J.; Simpson, T.W. 3D Printing Disrupts Manufacturing: How Economies of One Create New Rules of Competition. Res. Manag. 2013, 56, 12-16. [CrossRef]

87. Groom, R.C. Think global and Act Local. J. Extra. Corpor. Technol. 2012, 44, 177.

88. Geddes, P. Cities in Evolution-An Introduction to the Town Planning Movement and to the Study of Civics; Williams \& Norgate: London, UK, 1915.

89. Buehler, E.; Branham, S.; Ali, A.; Chang, J.J.; Hofmann, M.K.; Hurst, A.; Kane, S.K. Sharing is Caring: Assistive Technology Designs on Thingiverse. In Proceedings of the 33rd Annual ACM Conference on Human Factors in Computing Systems, Seoul, Korea, 18-23 April 2015; ACM: New York, NY, USA, 2015.

90. Open Assistive. Available online: https: / openassistive.org/ (accessed on 13 July 2021).

91. What We Want-Right to Repair Europe. Available online: https://repair.eu/what-we-want/ (accessed on 6 February 2021).

92. Manzini, E.; Vezzoli, C.; Clark, G. Product-Service Systems. Using an Existing Concept as a New Approach to Sustainability. J. Des. Res. 2001, 1, 27-40. [CrossRef]

93. Song, J.S.; Zhang, Y. Stock or Print? Impact of 3-d Printing on Spare Parts Logistics. Manag. Sci. 2020, 66, 3860-3878. [CrossRef]

94. Kostidi, E.; Nikitakos, N. Is It Time for the Maritime Industry to Embrace 3d Printed Spare Parts? TransNav Int. J. Mar. Navig. Saf. Sea Transp. 2018, 12, 557-564. [CrossRef]

95. Savastano, M.; Amendola, C.; D'Ascenzo, F.; Massaroni, E. 3-D Printing in the Spare Parts Supply Chain: An Explorative Study in the Automotive Iindustry. In Lecture Notes in Information Systems and Organisation; Springer: Berlin/Heidelberg, Germany, 2016; Volume 18, pp. 153-170.

96. Kretzschmar, N.; Chekurov, S.; Salmi, M.; Tuomi, J. Evaluating the Readiness Level of Additively Manufactured Digital Spare Parts: An Industrial Perspective. Appl. Sci. 2018, 8, 1837. [CrossRef]

97. Kirchherr, J.; Reike, D.; Hekkert, M. Conceptualizing the Circular Economy: An Analysis of 114 Definitions. Resour. Conserv. Recycl. 2017, 127, 221-232. [CrossRef]

98. Adya, M.; Samant, D.; Scherer, M.J.; Killeen, M.; Morris, M.W. Assistive/Rehabilitation Technology, Disability, and Service Delivery Models. Cogn. Process. 2012, 13, 75-78. [CrossRef] [PubMed]

99. Mukherjee, G.; Samanta, A. Wheelchair Charity: A Useless Benevolence in Community-Based Rehabilitation. Disabil. Rehabil. 2005, 27, 591-596. [CrossRef] [PubMed]

100. Kniskern, J.; Phillips, C.P.; Patterson, T. Technology (AT) Reutilization (Reuse): What We Know Today. Assist. Technol. Outcomes Benefits 2008, 5, 59-71.

101. Morgan, K.A.; Walker, C.; Walker, K. Assistive Technology Reutilization Program Outcomes—Wheel Mill System View project. In Proceedings of the 136st APHA Annual Meeting and Exposition, San Diego, CA, USA, 25-29 October 2008.

102. Wilcox, M.J.; Campbell, P.H.; Fortunato, L.; Hoffman, J. A First Look at Early Intervention and Early Childhood Providers' Reports of Assistive Technology Reuse. J. Spec. Educ. Technol. 2013, 28, 47-57. [CrossRef]

103. Sund, T. The Norwegian Model of Assistive Technology Provision. Presentation at the Global Research, Innovation and Education on Assistive Technology (GREAT). In Proceedings of the GREAT Summit, Geneva, Switzerland, 3-4 August 2017.

104. MacLachlan, M.; Banes, D.; Bell, D.; Borg, J.; Donnelly, B.; Fembek, M.; Ghosh, R.; Gowran, R.J.; Hannay, E.; Hiscock, D.; et al. Assistive Technology Policy: A Position Paper from the First Global Research, Innovation, and Education on Assistive Technology (GREAT) Summit. Disabil. Rehabil. Assist. Technol. 2018, 13, 454-466. [CrossRef]

105. Sanders, J.E.; Fatone, S. Residual Limb Volume Change: Systematic Review of Measurement and Management. J. Rehabil. Res. Dev. 2011, 48, 949-986. [CrossRef]

106. Williams, R.; Oldfrey, B.; Holloway, C. An AT Innovator Case Study: Amparo. Available online: https://at2030.org/an-atinnovator-case-study-amparo/ (accessed on 15 July 2021).

107. Wyss, D.; Lindsay, S.; Cleghorn, W.L.; Andrysek, J. Priorities in Lower Limb Prosthetic Service Delivery Based on an International Survey of Prosthetists in Low- and High-Income Countries. Prosthet. Orthot. Int. 2015, 39, 102-111. [CrossRef]

108. Vollmer, I.; Jenks, M.J.F.; Roelands, M.C.P.; White, R.J.; van Harmelen, T.; de Wild, P.; van der Laan, G.P.; Meirer, F.; Keurentjes, J.T.F.; Weckhuysen, B.M. Beyond Mechanical Recycling: Giving New Life to Plastic Waste. Angew. Chem. Int. Ed. 2020, 59, 15402-15423. [CrossRef] 